\title{
Combined Effect of Catholyte Gap and Cell Voltage on Syngas Ratio in Continuous $\mathrm{CO}_{2} / \mathrm{H}_{2} \mathrm{O}$ Co-electrolysis
}

\author{
Min Gwan $\mathrm{Ha}^{1,2 \dagger}$, Youngseung $\mathrm{Na}^{3 \dagger}$, Hee Young Park ${ }^{1}$, Hyoung-Juhn Kim ${ }^{1}$, Juhun Song ${ }^{2}$, \\ Sung Jong Yoo ${ }^{1}$, Yong-Tae Kim ${ }^{4 * * *}$, Hyun S. Park ${ }^{1,5 * *}$, and Jong Hyun Jang ${ }^{1,5,6 *}$ \\ ${ }^{1}$ Center for Hydrogen·Fuel Cell Research, Korea Institute of Science and Technology (KIST), Seoul 02792, Korea \\ ${ }^{2}$ School of Mechanical Engineering, Pusan National University, Busan 46241, Korea, \\ ${ }^{3}$ Department of Mechanical and Information Engineering, University of Seoul, Seoul 02504, Korea \\ ${ }^{4}$ Department of Materials Science and Engineering, Pohang University of Science and Technology (POSTECH), Pohang 37673, Korea \\ ${ }^{5}$ Division of Energy \& Environment Technology, KIST School, University of Science and Technology (UST), Seoul 02792, Korea \\ ${ }^{6}$ Graduate School of Energy and Environment (KU-KIST Green School), Korea University, Seoul 02841, Korea
}

\begin{abstract}
Electrochemical devices are constructed for continuous syngas $\left(\mathrm{CO}+\mathrm{H}_{2}\right)$ production with controlled selectivity between $\mathrm{CO}_{2}$ and proton reduction reactions. The ratio of $\mathrm{CO}$ to $\mathrm{H}_{2}$, or the faradaic efficiency toward $\mathrm{CO}$ generation, was mechanically manipulated by adjusting the space volume between the cathode and the polymer gas separator in the device. In particular, the area added between the cathode and the ion-conducting polymer using $0.5 \mathrm{M} \mathrm{KHCO}_{3}$ catholyte regulated the solution acidity and proton reduction kinetics in the flow cell. The faradaic efficiency of CO production was controlled as a function of the distance between the polymer separator and cathode in addition to that manipulated by the electrode potential. Further, the electrochemical $\mathrm{CO}_{2}$ reduction device using Au NPs presented a stable operation for more than $23 \mathrm{~h}$ at different $\mathrm{H}_{2}$ :CO production levels, demonstrating the functional stability of the flow cell utilizing the mechanical variable as an important operational factor.
\end{abstract}

Keywords : Electrocatalysis, $\mathrm{CO}_{2}$ Reduction, Syngas, Device, Membrane Electrode Assembly

Received : 17 February 2021, Accepted : 30 March 2021

\section{Introduction}

As a consequence of industrialization, the emission of greenhouse gases from the combustion of fossil fuels has continuously increased at an alarming rate in the past 800,000 years, reaching above 409 ppm in $2019[1,2]$. The accumulation of atmospheric carbon dioxide $\left(\mathrm{CO}_{2}\right)$, one of the major greenhouse gases, has caused serious climatic changes owing to which unpredictable and extreme weather events have occurred more frequently [3,4]. For this reason, the reduction of carbon dioxide emissions is currently a

\footnotetext{
†These authors contributed equally to this work

*E-mail address: jhjang@kist.re.kr (J.H Jang), hspark@kist.re.kr (H.S. Park), yongtae@postech.ac.kr (Y.-T. Kim)

DOI: https://doi.org/10.33961/jecst.2021.00220

This is an open-access article distributed under the terms of the Creative Commons Attribution Non-Commercial License (http://creativecommons.org/licenses/by-nc/4.0) which permits unrestricted non-commercial use, distribution, and reproduction in any medium, provided the original work is properly cited.
}

global concern [5]. Carbon capture, utilization, and storage (CCUS) is an important process for reducing the greenhouse gas concentration by utilizing the waste $\mathrm{CO}_{2}$ from industrialized facilities [6-9].

The electrochemical $\mathrm{CO}_{2}$ reduction reaction (eCORR) is a CCUS technology used to produce value-added chemicals, including $\mathrm{CO}$, alcohols, and hydrocarbons using waste $\mathrm{CO}_{2}$ and electricity $[10,11]$. In particular, $\mathrm{CO}$ is an invaluable stock material used for the Fischer-Tropsch process to produce various liquid hydrocarbons [12]. Synthesis gas (syngas) is a gaseous mixture of $\mathrm{CO}$ and $\mathrm{H}_{2}$ used to produce a variety of chemicals, depending on the mixture composition, such as hydrogen $\left(\mathrm{H}_{2} / \mathrm{CO} \geq 50\right)$, ethanol $\left(\mathrm{H}_{2} / \mathrm{CO} \leq 1\right)$, and methanol $\left(\mathrm{H}_{2} / \mathrm{CO}=2\right)$ [13]. The e-CORR catalyst has been rigorously developed with metal catalysts, such as Au [14-19], Ag [20], Zn [21,22], $\mathrm{Cu}$ [23], Ag-Cu [24], Ag-Sn [25], $\mathrm{Cu}-\mathrm{Au}$ [26], and $\mathrm{Cu}-\mathrm{Pd}$ [27]. Among them, $\mathrm{Au}$ and $\mathrm{Ag}$ nanoparticles have been reported to have higher 
selectivity toward $\mathrm{CO}$ production, where the weak $\mathrm{CO}$ adsorption onto the surfaces generates $\mathrm{CO}$ as the major product of e-CORR [14]. For example, $\mathrm{Au}$ nanoparticles with a size of $8 \mathrm{~nm}$ showed significant faradaic efficiency up to $90 \%$ for CO production at $-0.67 \mathrm{~V}_{\mathrm{RHE}}$ [15]. Despite the active discovery of eCORR catalysts, limited studies have been reported on the construction of electrochemical apparatus for practical and continuous $\mathrm{CO}$ production through eCORR.

The effective incorporation of e-CORR catalysts into applicable devices and their stable operation is essential for the use of CCUS as a climate remediation technology. Certain previous studies have demonstrated the production of CO using gas-diffusion electrodes and e-CORR catalysts [28-31]. The apparent device performance depends on three factors: i) mass transport of $\mathrm{CO}_{2}$ to the electrode surface, ii) electron and ion conductivities through the supporting electrode or electrolyte to the active catalyst, and iii) favorable reaction kinetics at the catalyst surface with an appropriate chemical environment, such as $\mathrm{pH}$, regulating the reaction activity and selectivity. Different cell configurations and operation methods have been suggested to control the operational factors for practical e-CORR.

For example, Delacourt et al. suggested the importance of a small gap between the membrane separator and e-CORR cathode of the e-CORR device, named $\mathrm{E}_{\text {gap }}$ in this study; therefore, the presence of a buffered electrolyte near the active catalyst is important for the supply of $\mathrm{CO}_{2}$ and to adjust the local $\mathrm{pH}$ $[28,29]$. However, in the report, the product composition, that is, the ratio of $\mathrm{CO}$ to $\mathrm{H}_{2}$ produced by the eCORR device, significantly changed over a few hours of continuous operation, and therefore, was inappropriate for practical applications [28]. The effect of operational parameters, such as $\mathrm{CO}_{2}$ gas pressure, catholyte flow rate, cell temperature, and applied current density, was investigated to control the syngas ratio produced by the device [30,31]. Longer time duration and stable operation up to $5 \mathrm{~h}$ was demonstrated with different $\mathrm{H}_{2}$ : $\mathrm{CO}$ ratios, where the product composition or syngas ratio $\left(\mathrm{H}_{2}: \mathrm{CO}\right)$ was mainly modified from 1.5 to 2 by changing the device voltage from approximately 3 to $4 \mathrm{~V}$ [30]. In most of the previous reports on e-CORR device operation, the production rate, that is, the operating current and device voltage had to be changed simultaneously to control the product composition.

Herein, we demonstrate that the $\mathrm{H}_{2}$ : $\mathrm{CO}$ ratio produced by the e-CORR device can be controlled by simply adjusting the mechanical parameters of the device. The e-CORR device has been reported to exhibit stable and continuous syngas production for over $23 \mathrm{~h}$. By manipulating the $\mathrm{E}_{\text {gap }}$, that is, the distance between the cathode and ion-conducting separator, the faradaic efficiency of $\mathrm{CO}$ production was changed in addition to the voltage changes. The eCORR device demonstrated in this study suggests a simple mechanical design factor to control the syngas ratio and total production rate.

\section{Experimental}

\subsection{Electrode Preparation}

Au nanoparticles (NPs) were synthesized in the presence of polyethylenimine (PEI-Au/C) as an eCORR catalyst [32]. Briefly, the PEI-Au/C powder was synthesized by the chemical reduction of $\mathrm{HAu}-$ $\mathrm{Cl}_{4} \cdot 3 \mathrm{H}_{2} \mathrm{O}$ (Sigma-Aldrich, St. Louis, MO, USA, $99.9 \%$ ) using $\mathrm{NaBH}_{4}$ (Sigma-Aldrich, $99 \%$,) in the presence of PEI (Sigma-Aldrich, $50 \mathrm{wt} . \%$ in water, $\mathrm{Mw} 2000$ ) in an ethanol solution. The e-CORR catalyst was supported on porous carbon powder (Cabot Corporation, Boston, Massachusetts, USA, Vulcan $\mathrm{XC}-72$ ). The e-CORR and oxygen evolution reaction (OER) catalysts were coated onto the supporting electrode, that is, carbon paper (Toray Industries Inc., Tokyo, Japan, TGP-H-090 porosity 78\%) and titanium paper (Bekaert Inc., Zwevegem, Belgium, Tipaper250), respectively, for making up the cathode and anode. The loading amount of the catalyst at the cathode and anode was maintained at approximately $1 \mathrm{mg} \mathrm{cm}^{-2}$. the electrode layered with the catalyst, $1 \mathrm{mg}$ of PEI-Au/C NPs was mixed with $8.57 \mathrm{mg}$ of Nafion ionomer solution (Sigma-Aldrich, 5 wt.\% in lower aliphatic alcohols and 15-20\% water) and $61.86 \mathrm{mg}$ of isopropyl alcohol (Honeywell, Charlotte, North Carolina, USA, Meet ACS Specifications, $99.9 \%$ ) to form a catalyst solution. The Nafion ionomer content was $30 \mathrm{wt} . \%$ of the total solid content in the catalyst solution. After dispersion of the solution via ultrasonication for $30 \mathrm{~min}$, the mixture was sprayed onto one side of the carbon paper using the hand spray method. For the OER, $1 \mathrm{mg}$ of $\mathrm{IrO}_{2}$ NPs (Alfa Aesar Inc., Haverhill, Massachusetts, USA, Iridium(IV) oxide, 99.99\%) was mixed with 
$1.08 \mathrm{mg}$ of Nafion ionomer solution and $50.63 \mathrm{mg}$ of isopropyl alcohol to form the catalyst solution. The Nafion ionomer content was $5.15 \mathrm{wt} . \%$ of the total solid content of the catalyst solution. The mixture was sonicated for $30 \mathrm{~min}$ and subsequently, the solution was sprayed onto the titanium paper surface using the hand spray method.

\subsection{Half-cell Measurements}

$\mathrm{PEI}-\mathrm{Au} / \mathrm{C}$ electrode was inserted into a $0.5 \mathrm{M}$ $\mathrm{KHCO}_{3}$ aqueous solution (Sigma-Aldrich, 99.7\%) saturated with $\mathrm{CO}_{2}$ (Sinyang Oxygen, Seoul, Korea, 99.99\%) or Ar (Sinyang Oxygen, 99.999\%). Deionized water was used as the solvent. $\mathrm{An} \mathrm{Ag} / \mathrm{AgCl}$ electrode or a saturated calomel electrode (SCE) and a $\mathrm{Pt}$ mesh were used as the reference and counter electrodes, respectively. Nafion Membrane NRE-212 (DuPont Inc., Wilmington, Delaware, USA, $\mathrm{H}^{+}$form) was used as the separator between the cathode and anode in a three-electrode H-type cell. The relationship between the potential difference and current was measured using a potentiostat (BioLogic, SeyssinetPariset, France, HCP-803).

\subsection{Device Assembly}

The electrochemical cell used for $\mathrm{CO}$ production was fabricated as described below. A homemade graphite block with a serpentine flow channel served as the cathode flow plate and current collector, while a titanium block with a flow channel was used as the anode current collector. To ensure the chemical and electrochemical stabilities of the anode under oxidative OER environment, titanium paper and titanium block were used as the gas-diffusion layer (GDL) and current collector, respectively. A membrane electrode assembly (MEA) with a geometric surface area of $9 \mathrm{~cm}^{2}$ was fabricated by placing the anode and cathode on both sides of the proton conducting membrane (Nafion membrane, NRE-212, DuPoint Inc.). A polytetrafluoroethylene (PTFE) rubber gasket with a specific thickness of 100 or $200 \mu \mathrm{m}$ was inserted, whenever necessary, between the cathode and polymer separator of the MEA to control the $\mathrm{E}_{\text {gap }}$. Thereafter, the MEA was inserted between the anode and cathode current collector.

\subsection{Device Operation}

An aqueous solution of $0.5 \mathrm{M} \mathrm{KHCO}_{3}$ (SigmaAldrich, 90\%) and 0.5 M KOH (Sigma-Aldrich,
90\%) were used as the catholyte and anolyte, respectively, for the e-CORR device operation. $0.5 \mathrm{M}$ $\mathrm{KHCO}_{3}$ aqueous solution saturated with $\mathrm{CO}_{2}$ ( $\mathrm{Sin}$ yang Oxygen, 99.99\%) and gaseous $\mathrm{CO}_{2}$ at atmospheric pressure was mixed and fed into the cathode through a Y-shaped tube connector at a flow rate of $10 \mathrm{~mL} / \mathrm{min}$ for both the gas and liquid. $0.5 \mathrm{M} \mathrm{KOH}$ solution was supplied to the anode at a flow rate of $10 \mathrm{~mL} / \mathrm{min}$. The flow was controlled using a peristaltic pump (Masterflex Inc., Gelsenkirchen, Germany, model no. 07523-90). The cell voltage was regulated from -1.8 to $-3.0 \mathrm{~V}$ using a potentiostat (HCP803 ) while measuring the device current, and the electrochemical impedance spectroscopy (EIS) data were collected in the frequency range of $100 \mathrm{kHz}-$ $50 \mathrm{mHz}$ with a voltage amplitude of $10 \mathrm{mV}$.

\subsection{Characterization}

The products of the $\mathrm{CO}_{2}$ reduction reactions in both the half-cell and full-cell experiments were analyzed using a gas chromatograph (GC, Agilent Technologies Inc., 7890B GC) equipped with a thermal conductivity detector (TCD) and a methanizer-flame ionization detector (methanizer-FID). The GC was calibrated for $\mathrm{CO}, \mathrm{H}_{2}, \mathrm{CH}_{4}, \mathrm{CO}_{2}$, and $\mathrm{N}_{2}$. Ar was used as the carrier gas for $\mathrm{GC}$ measurements. A digital flow meter (Agilent Technologies Inc., ADM2000) was employed to quantify the flow rate at the outlet of the GC equipment. The amount of CO produced and the $\mathrm{CO}$ partial current density were estimated by the gas flow rate and $\mathrm{CO}$ concentration obtained from GC. Field emission scanning electron microscopy (FE-SEM) images of the prepared GDE were recorded with an S-4200 (Hitachi Inc., Ibaraki, Japan). Transmission electron microscopy (TEM, FEI TITAN ${ }^{\mathrm{TM}} 80-300$ ) was used to observe the asprepared PEI-Au/C catalyst. X-ray diffraction (XRD) measurements were performed using a D/Max 2500 v/PC (Rigaku Co., Tokyo Japan) with $\mathrm{Cu}-\mathrm{K} \alpha$ radiation (40 kV, $1.5406 \AA$ ). Thermogravimetric analysis (TGA, Q50, TA Instruments) was conducted in air at a ramp rate of $10 \mathrm{~K} / \mathrm{min}$.

\section{Results and Discussion}

\subsection{Half-cell measurement}

PEI-Au/C was selected as the e-CORR catalyst [32,33]. As reported previously, Au NPs synthesized in the presence of PEI have a smaller size of $3 \mathrm{~nm}$ for 
(a)

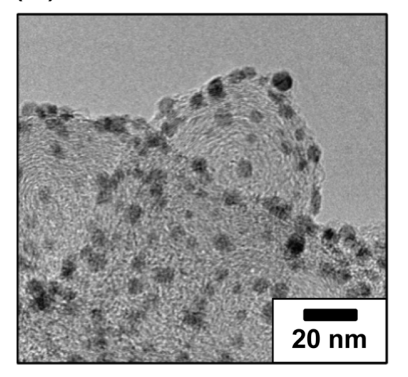

(b)

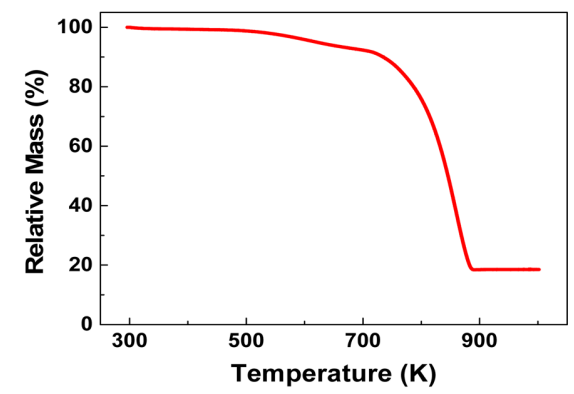

(c)

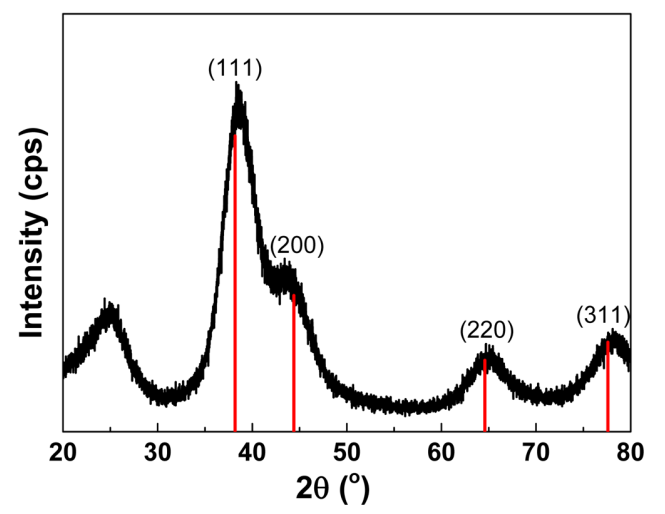

Fig. 1. (a) TEM images, (b) TGA measurement and (c) XRD patterns performed for PEI-Au/C. The diffraction peaks at approximately $38^{\circ}, 44^{\circ}, 65^{\circ}$ and $78^{\circ}$ can be indexed to (1 111$),\left(\begin{array}{lll}2 & 0 & 0\end{array}\right),\left(\begin{array}{lll}2 & 2 & 0\end{array}\right)$ and $\left(\begin{array}{lll}3 & 1 & 1\end{array}\right)$ planes of face-centered cubic (fcc) crystalline $\mathrm{Au}$, respectively (JCPDS standard 04-0784(Au)).

enhanced $\mathrm{CO}_{2}$ reduction activity [32]. The catalyst NPs supported on a highly conductive carbon presented a uniform size distribution (size of approximately $100 \mathrm{~nm}$ ), as shown in the TEM image (Fig. 1a). The amount of the active catalyst was adjusted to approximately $20 \mathrm{wt} . \%$ as evidenced from the TGA analysis (Fig. 1b). In the TGA analysis, PEI and carbon were completely oxidized at $923.15 \mathrm{~K}$, while the $\mathrm{Au}$ NPs remained. Further, the crystal size of the $\mathrm{Au}$ NPs, as estimated by the Scherrer equation, and calculated using the (220) peak broadening of the facecentered cubic Au crystals in the XRD patterns, was found to be approximately $2 \mathrm{~nm}$, which is in good agreement with the apparent size observed under the microscope (Fig. 1a and c). This implies that the NPs layered on the carbon support form a solid crystal with insignificant particle agglomerations.

The electrochemical proton reduction activity of the PEI-Au/C catalyst was first investigated in three different aqueous electrolyte solutions under an $\mathrm{Ar}$ atmosphere (Fig. 2a, stationary electrode). As expected, the Au catalyst showed significant overpotential for the proton reduction reaction. It is essential to have an overpotential greater than $0.5 \mathrm{~V}$ to initiate the Hydrogen evolution reaction (HER) even in a strongly acidic solution, that is, $0.5 \mathrm{M} \mathrm{H}_{2} \mathrm{SO}_{4}$ solution (pH 0.3 ), and approximately $2 \mathrm{~V}$ for a strong basic solution ( $\mathrm{pH}$ 13.7, $1 \mathrm{M} \mathrm{KOH,} \mathrm{Fig.} \mathrm{2a).} \mathrm{Furthermore,}$ no exponential increase of the HER current was observed up to a cathode potential of $-2.5 \mathrm{~V}_{\mathrm{RHE}}$ at the $\mathrm{PEI}-\mathrm{Au} / \mathrm{C}$ catalyst in a neutral aqueous solution $(\mathrm{pH}$ 7.2, $0.5 \mathrm{M} \mathrm{KHCO}_{3}$ ). As the mitigation of HER activity is important for e-CORR catalysis, it was decided to use $0.5 \mathrm{M} \mathrm{KHCO}_{3}$ aqueous solution as the $\mathrm{CO}_{2}$ reduction medium for further experiments.

In the $\mathrm{CO}_{2}$ saturated $0.5 \mathrm{M} \mathrm{KHCO}_{3}$ aqueous solu- 
tion, the PEI-Au/C catalyst exhibited significant eCORR activity at potentials more negative than -0.4 $\mathrm{V}_{\mathrm{RHE}}$ (Fig. 2b, rotating ring-disk electrode (RRDE) measurement). The on-set potential of the e-CORR at the PEI-Au/C catalyst was approximately $-0.4 \mathrm{~V}_{\mathrm{RHE}}$, and the current density exponentially increased at a potential up to $-1.3 \mathrm{~V}_{\mathrm{RHE}}$; subsequently, it reached a saturation current density of approximately $30 \mathrm{~mA} /$ $\mathrm{cm}^{2}$. A volcano-shaped CO faradaic efficiency was observed at the PEI-Au/C electrode, and the maximum CO faradaic efficiency was approximately $45 \%$ at $-0.7 \mathrm{~V}_{\mathrm{RHE}}$. The faradaic efficiency continuously decreased when the potential was shifted to values more negative than $-0.7 \mathrm{~V}_{\mathrm{RHE}}$, which facilitated HER activity.

Based on the fundamental investigation of the PEI-

(a)

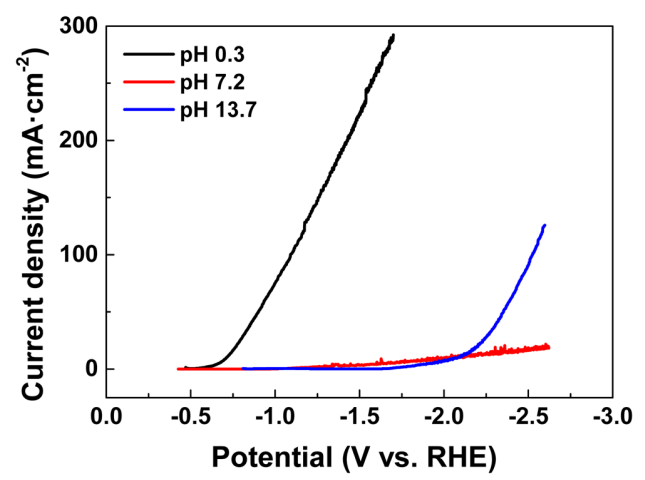

(b)

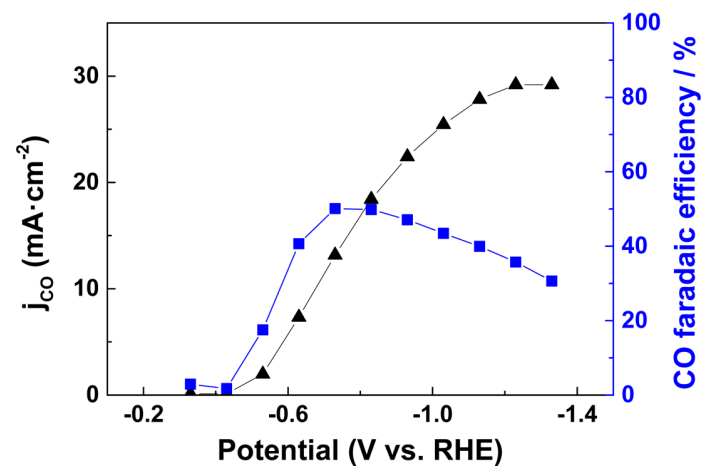

Fig. 2. (a) Linear sweep voltammetry performed at PEI$\mathrm{Au} / \mathrm{C}$ in different $\mathrm{pH}$ solutions during the hydrogen evolution reaction measured at a stationary electrode and (b) calculated CO production current and CO F.E. at PEI$\mathrm{Au} / \mathrm{C}$ in $\mathrm{pH} 7.2$ electrolyte solution measured at a rotating ring-disk electrode.
$\mathrm{Au} / \mathrm{C}$ electrode in half-cell experiments, $\mathrm{a} \mathrm{CO}_{2}$ saturated neutral aqueous electrolyte was selected as the catholyte for facile e-CORR without dominant HER activity for the two-electrode full-cell device. $0.5 \mathrm{M}$ $\mathrm{KOH}$ aqueous solution and $\mathrm{IrO}_{2}$ catalyst were selected as the anolyte and OER catalyst, respectively, for the device.

\subsection{Device measurement}

Fig. 3 reveals the images of porous GDE coated with the PEI-Au/C catalyst on the surfaces. The carbon paper is composed of a carbon fiber with a length of hundreds of micrometers and PTFE resin (5 wt.\%), and large pores are formed between the carbon fibers for appropriate mass transportation of the liquid electrolyte (Fig. 3a). It is also clearly visible that the PEI-Au/C catalyst was uniformly layered on the carbon fiber surfaces, where no large agglomeration of the catalyst was observed (Fig. 3b). The catalyst layer itself contains sub-micro pores between the catalyst particles, thus providing a large surface area for the e-CORR (Figs. 3c and d). The microscopic images exhibited an evenly distributed catalyst on carbon paper using the hand spray method on the GDE.

Using the PEI-Au/C-coated GDE and $\mathrm{IrO}_{2} / \mathrm{Ti}$-PTL electrodes, an e-CORR device was constructed (a)

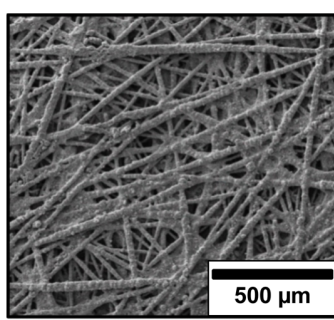

(c)

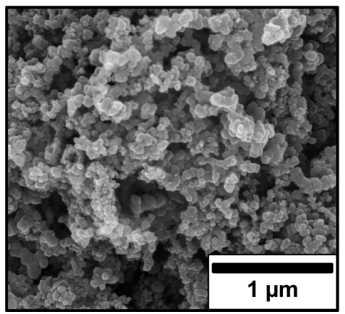

(b)

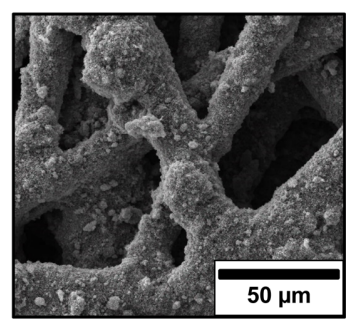

(d)

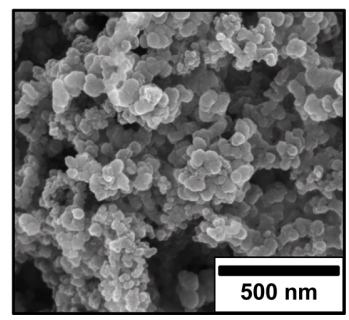

Fig. 3. SEM images of surface cathode GDE (PEI-Au/C on carbon paper). 


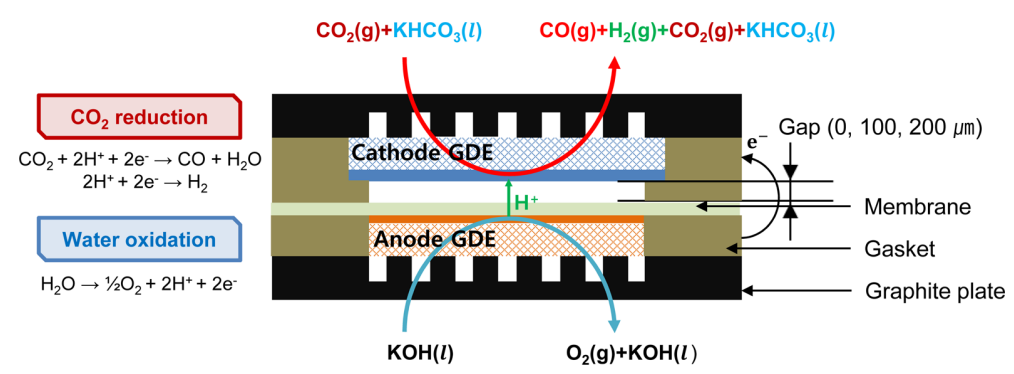

Scheme 1. Schematic diagram of $\mathrm{CO}_{2}$ reduction cell structures.

(Scheme 1). The cathode and anode were placed on either sides of the ion-conducting perfluorinated membrane. The anode was closely attached to the membrane, while the $\mathrm{E}_{\text {gap }}$ was controlled between 0 and $200 \mu \mathrm{m}$. In particular, the $\mathrm{E}_{\text {gap }}$ was modified by inserting a PTFE spacer with thicknesses of 0,100 , and $200 \mu \mathrm{m}$. As discussed above, the cathode structure examined in this study was previously introduced by Delacourt et al.; therefore, the $\mathrm{E}_{\text {gap }}$ affects the buffer capacity of the electrolyte around the electrode, resulting in different $\mathrm{CO}$ faradaic efficiencies as a function of the gap distance [28]. However, a fixed amount of electrolyte was impregnated into the cathode before the device operation, and the device was only operated for a limited duration in the previous report. In this study, the same cathode structure was adopted with three different gap distances, that is, 0,100 , and $200 \mu \mathrm{m}$; however, the electrolyte was continuously supplied to the flow cell. Without the electrolyte supply to the reactor, the surface $\mathrm{pH}$ of the cathode should be constantly changed as the reaction proceeds in the confined electrolyte, such as in bulk electrolysis. The flow cell, shown in Scheme 1, was operated for stable and longer duration electrolysis at steady state in this study, as discussed below.

The current density-voltage relationship, or I-V curves, of the e-CORR devices in $0.5 \mathrm{M} \mathrm{KHCO}_{3}$ catholyte are plotted in Fig. 4. To construct the I-V curves, chronoamperometry was performed for 30 min at voltages ranging between -1.8 and $-3.0 \mathrm{~V}$, and the average total current density at each voltage can be obtained from the curves. As the electromotive force, or the device voltage increased, the total current for both proton and $\mathrm{CO}_{2}$ reduction reactions also increased for all the devices with different $\mathrm{E}_{\text {gap }}$ values. The current densities of the different devices at voltages lower than $-2.0 \mathrm{~V}$ were similar, that is, approximately $10 \mathrm{~mA} / \mathrm{cm}^{2}$. However, the total cur-

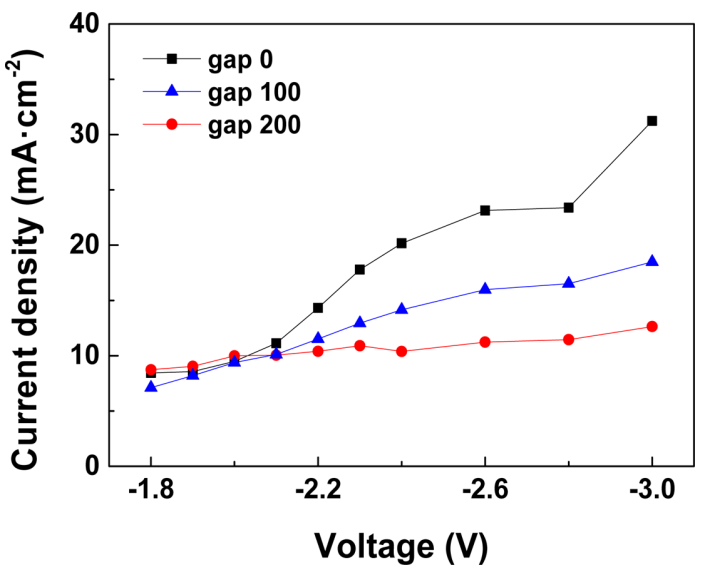

Fig. 4. Total current density at PEI-Au/C electrode measured at gap 0,100 , and $200 \mu \mathrm{m}$ in a two-electrode single cell device for syngas production.

rent density increments with increased cell voltages were different with different $\mathrm{E}_{\text {gap }}$; therefore, the total current density reached higher than $30 \mathrm{~mA} / \mathrm{cm}^{2}$ at $E_{\text {gap }}=0 \mu \mathrm{m}$, and decreased to 16 and $12 \mathrm{~mA} / \mathrm{cm}^{2}$ at an $E_{\text {gap }}$ of 100 and $200 \mu \mathrm{m}$, respectively, at $-3.0 \mathrm{~V}_{\mathrm{RHE}}$.

More importantly, the reaction selectivity toward $\mathrm{CO}_{2}$ reduction was significantly affected by the $\mathrm{E}_{\text {gap }}$. The $\mathrm{CO}$ faradaic efficiency decreased as the device voltage increased beyond $-1.9 \mathrm{~V}$ when the $\mathrm{E}_{\text {gap }}$ was less than $100 \mu \mathrm{m}$; however, the CO faradaic efficiency increased from approximately 5 to $37.3 \%$ as the voltage increased from -1.8 to $-3.0 \mathrm{~V}$ for $\mathrm{E}_{\text {gap }}=$ $200 \mu \mathrm{m}$. The decreased CO production selectivity at large overpotentials is often explained by the rapidly facilitated proton reduction reactions at further negative potentials, compared to that of $\mathrm{CO}_{2}$ reduction reactions, as observed in the case of $\mathrm{E}_{\mathrm{gap}}=0$ and $100 \mu \mathrm{m}$ [34]. However, the proton reduction reaction was effectively reduced at $\mathrm{E}_{\mathrm{gap}}=200 \mu \mathrm{m}$. In the e- 

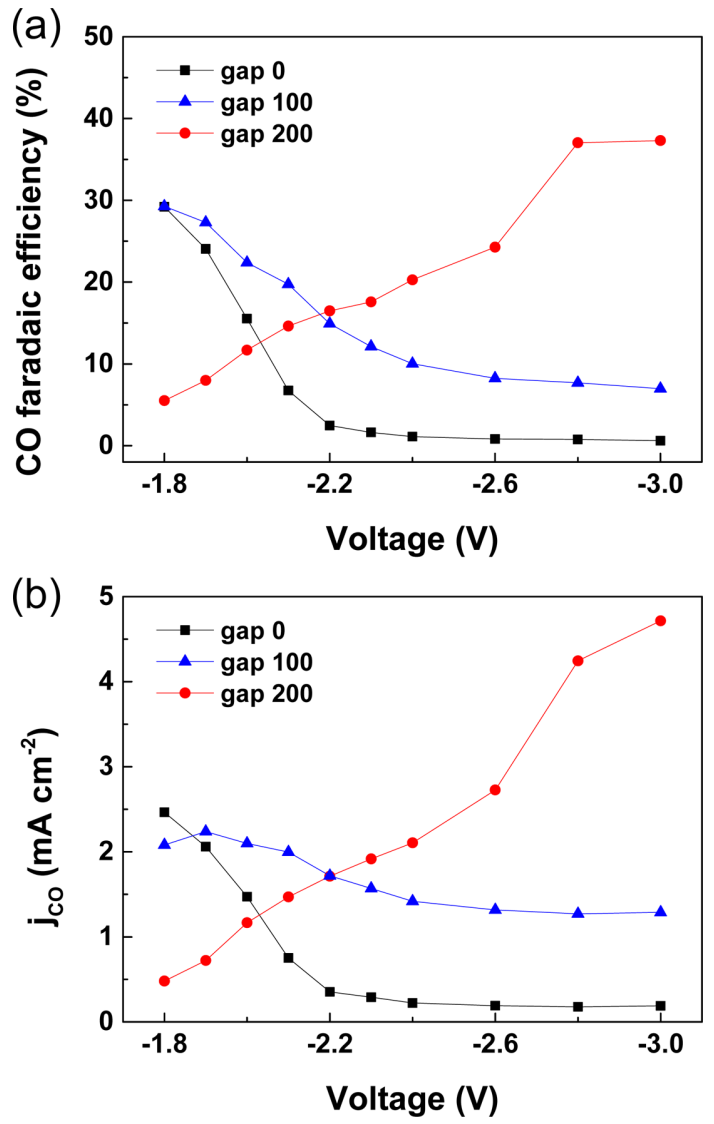

Fig. 5. Electrochemical $\mathrm{CO}_{2}$ reduction activities of PEI$\mathrm{Au} / \mathrm{C}$ with different gap. (a) CO F.E and (b) CO partial current density measured at gap $0 \mu \mathrm{m}, 100 \mu \mathrm{m}$ and $200 \mu \mathrm{m}$ in a two-electrode single cell device for syngas production.

CORR device, the excess protons present in the cathode are generated at the oxygen evolution anode and transported through the ion-conducting membrane to the cathode surface. As the $E_{\text {gap }}$ is increased, the excess protons from the anode are washed out by the catholyte and the surface acidity of cathode is regulated to $\mathrm{pH} 7.2\left(0.5 \mathrm{M} \mathrm{KHCO}_{3}\right.$, equation 1) [28].

$$
\mathrm{H}^{+}+\mathrm{HCO}_{3}{ }^{-} \rightarrow \mathrm{CO}_{2}+\mathrm{H}_{2} \mathrm{O}
$$

As shown in Fig. 2, the proton reduction kinetics are influenced dominantly by $\mathrm{pH}$, and they are significantly mitigated in the neutral carbonate electrolyte. The $\mathrm{E}_{\text {gap }}$ calculated by Delacourt et al. to maintain a neutral $\mathrm{pH}$ at the cathode surface was greater than $200 \mu \mathrm{m}$, which supports the experimen-

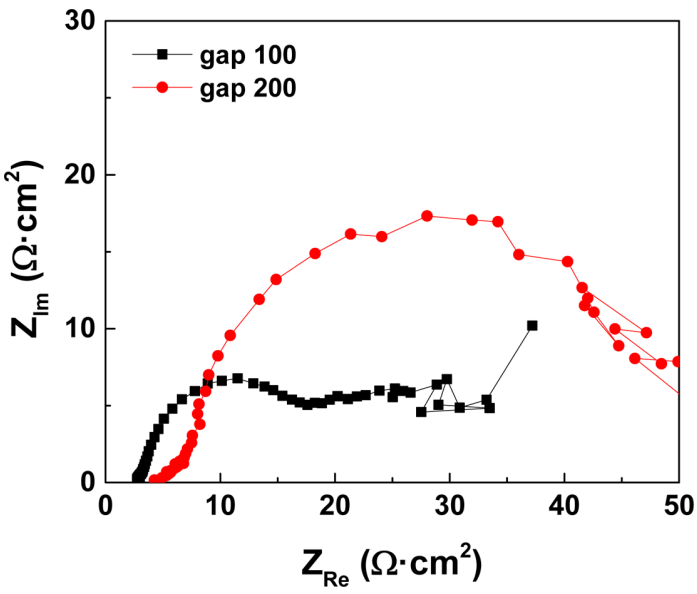

Fig. 6. Electrochemical impedance spectroscopy $(1 \mathrm{~Hz}$ $\sim 50 \mathrm{kHz})$ of two-electrode single cell device with different gap at $-2.4 \mathrm{~V}$.

tal results shown in this study [29]. In addition, $\mathrm{CO}_{2}$ produced from the reaction between the protons and carbonate electrolyte can be further used in e-CORR. In the device with $\mathrm{E}_{\text {gap }}=200 \mu \mathrm{m}$, the $\mathrm{CO}$ faradaic efficiency and $\mathrm{CO}$ production current successfully increased at a large device voltage, that is, approximately $5 \mathrm{~mA} / \mathrm{cm}^{2}$ at $-3.0 \mathrm{~V}$, whereas, current values of only 0.2 and $1.3 \mathrm{~mA} / \mathrm{cm}^{2}$ were obtained at $\mathrm{E}_{\text {gap }}=0$ and $100 \mu \mathrm{m}$, respectively, (Fig. 5b)

An additional effect caused by the large $\mathrm{E}_{\text {gap }}$ is the rise in the ohmic voltage drop owing to the increased ion-transfer resistance between the electrodes [35]. The ion-transfer resistance was measured using EIS (Fig. 6). High frequency resistance increased slightly with an increase in the $E_{\text {gap }}$, that is, from 3 to $4.3 \mathrm{ohm}$ $\mathrm{cm}^{2}$ for $E_{\text {gap }}$ of 100 and $200 \mu \mathrm{m}$, respectively, at $-2.4 \mathrm{~V}$ (Fig. 6). However, the ohmic voltage drop increase caused by the ion-transfer resistance at different $E_{\text {gap }}$ values was less than a few tens of $\mathrm{mV}$ at a total current density of less than $30 \mathrm{~mA} / \mathrm{cm}^{2}$; hence, it is not the main factor affecting the I-V curves with different $\mathrm{E}_{\text {gap }}$ values. In contrast, the charge transfer resistance significantly increased with enlarged $E_{\text {gap }}$ (Fig. 6 black square and red circle for $\mathrm{E}_{\text {gap }}$ of 100 and $200 \mu \mathrm{m}$, respectively), which is in good agreement with the reduced proton reduction kinetics at the large $\mathrm{E}_{\text {gap }}$.

Finally, the e-CORR device with different $\mathrm{E}_{\text {gap }}$ values was operated for more than $23 \mathrm{~h}$ to demonstrate practical syngas production. In Fig. 7, the mechanical 

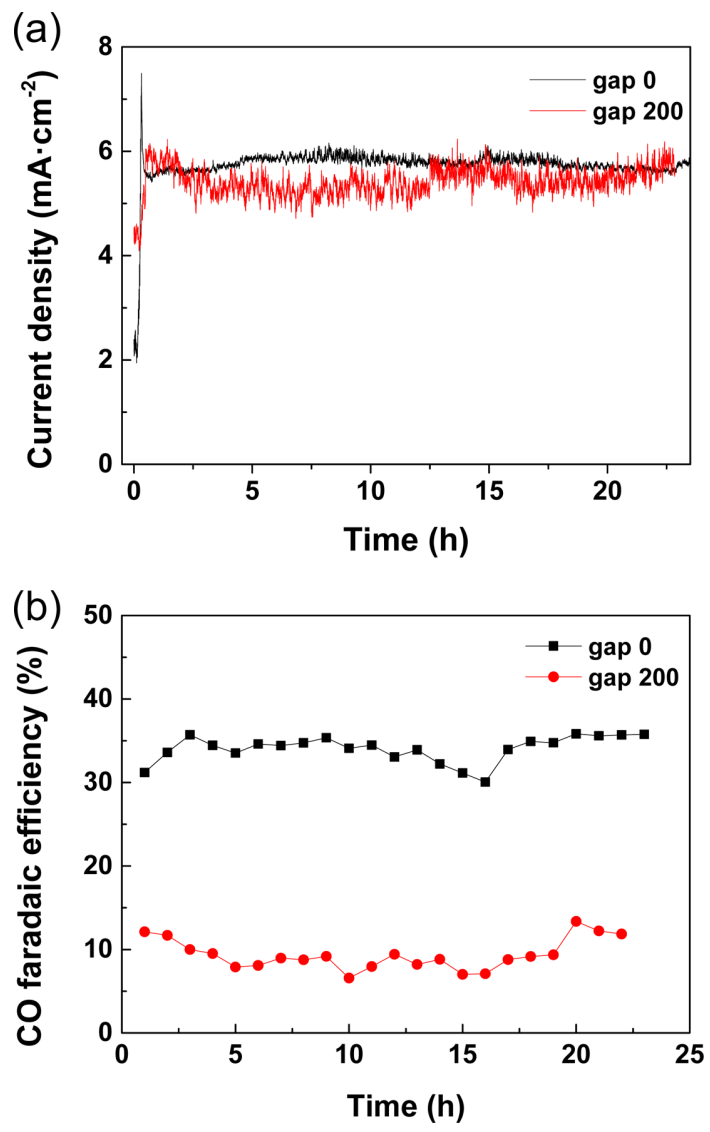

Fig. 7. The stability of PEI-Au/C over $24 \mathrm{hr}$ at $-2.0 \mathrm{~V}$ measured (a) total current density and (b) CO F.E. at gap $0 \mu \mathrm{m}$ and $200 \mu \mathrm{m}$ in a two-electrode single cell device for syngas production.

operation factor, that is, the $\mathrm{E}_{\text {gap }}$, was controlled to 0 and $200 \mu \mathrm{m}$ for two different $\mathrm{H}_{2}$ : $\mathrm{CO}$ ratios of the product gas stream, while the total registered current density was maintained between 5 and $6 \mathrm{~mA} \mathrm{~cm}^{-2}$ at $-2.0 \mathrm{~V}$. For the devices with $\mathrm{E}_{\mathrm{gap}}=0$ and $200 \mu \mathrm{m}$, respectively, $\mathrm{CO}$ faradaic efficiency was maintained at approximately 37 and $10 \%$ for more than $23 \mathrm{~h}$. The different $\mathrm{CO}$ faradaic efficiencies at $-2.0 \mathrm{~V}$ with different $E_{\text {gap }}$ in longer term operations are actually explained with those obtained at approximately $1.8 \mathrm{~V}$ in Fig. 5 for short period analysis. We believe the discrepancy between Fig. 5 and 7 was from experimental errors, such as insignificant difference in the cell assemble pressure or the difference in gasket compressibility for different measurements resulting in few tens $\mu \mathrm{m}$ changes of the gap. How- ever, it is still clear that the cathode-membrane gap is one of the important control factors affecting the faradaic efficiency in both Fig. 5 and 7. Further, the modification of $\mathrm{CO}$ faradaic efficiency at different $\mathrm{E}_{\text {gap }}$ should be more obvious given the cell voltage increased as estimated in Fig. 5. The control of syngas production with different $\mathrm{H}_{2} / \mathrm{CO}$ values is important for thermochemical hydrocarbon production through the Fischer-Tropsch process. For example, the syngas ratio of $\mathrm{H}_{2} / \mathrm{CO}=2$ with $\mathrm{E}_{\text {gap }}=0 \mu \mathrm{m}$ can be used for low temperature Fischer-Tropsch process (LTFT), and syngas ratio of $\mathrm{H}_{2} / \mathrm{CO}=9$ with $\mathrm{E}_{\text {gap }}=200 \mu \mathrm{m}$ is suitable for the high-temperature Fischer-Tropsch process (HTFT) for methane production [12].

In this study, it was demonstrated that the $\mathrm{H}_{2} / \mathrm{CO}$ value is modulated by controlling the $\mathrm{E}_{\text {gap }}$, a mechanical design factor of the e-CORR device, while the total current density and device voltage were conserved at the same value. Although Delacourt et al. utilized the same cathode structure with $\mathrm{E}_{\mathrm{gap}}=$ $800 \mu \mathrm{m}$ in a previous report, the operation was unstable as the $\mathrm{CO}$ faradaic efficiency decreased from 82 to $61 \%$ in $7 \mathrm{~h}$ without a continuous supply of the catholyte to the cathode. [28]. Herein, notably, it was a long-term operation with stable CO faradaic efficiency and current flow achieved for the first time by using a flow cell device with tunable $\mathrm{E}_{\text {gap }}$.

\section{Conclusions}

The effect of the gap between the cathode and the membrane on the e-CORR was investigated in a fullcell device. By controlling the mechanical aspect of the electrochemical device, the syngas composition and $\mathrm{CO}$ faradaic efficiency were controlled from $10 \%$ to $37 \%$. The electrolyte flow between the cathode and membrane can modulate the acidity and proton reduction kinetics at the cathode; therefore, proton reduction was effectively suppressed with $\mathrm{E}_{\text {gap }}$ $=200 \mu \mathrm{m}$. The e-CORR device was continuously operated for more than $23 \mathrm{~h}$ at two different $\mathrm{E}_{\text {gap }}$ values, that is, 0 and $200 \mu \mathrm{m}$, and stable syngas production was demonstrated with a CO faradaic efficiency of approximately 37 and $10 \%$ for the LTFT and HTFT, respectively. The cell structure presented in this study is appropriate for large-scale e-CORR devices with versatile mechanical operation factors, such as $\mathrm{E}_{\mathrm{gap}}$, to regulate the syngas composition. 


\section{Acknowledgment}

This study was supported by the Korea CCS R\&D Center (KCRC) grant funded by the Korean government (Ministry of Science and ICT (MSIT)) (No. 2013M1A8A1038315), the Hydrogen Energy Innovation Technology Development Program of the National Research Foundation of Korea (NRF) funded by the Korean government (MSIT) (No. 2019M3E6A1063674), and the Korea Institute of Energy Technology Evaluation and Planning (KETEP) grant funded by the MOTIE (No. 20173010032210 and No. $2019281010007 \mathrm{~A})$. This study was also financially supported by the Institutional Project of Korean Institute of Science and Technology (KIST).

\section{References}

[1] R. Lindsey, Climate Change: Atmospheric Carbon Dioxide, 2020.

[2] W. Wang, Y. Yung, A. Lacis, T. Mo, J. Hansen, Science, 1976, 194(4266), 685-690.

[3] D.A. Lashof, D.R. Ahuja, Nature, 1990, 344(6266), 529-531.

[4] C. Le Quéré, M.R. Raupach, J.G. Canadell, G. Marland, Nat. Geosci., 2009, 2(12), 831-836.

[5] M.I. Hoffert, K. Caldeira, G. Benford, D.R. Criswell, C. Green, H. Herzog, A.K. Jain, H.S. Kheshgi, K.S. Lackner, J.S. Lewis, Science, 2002, 298(5595), 981-987.

[6] K. Riahi, E.S. Rubin, M.R. Taylor, L. Schrattenholzer, D. Hounshell, Energy Economics, 2004, 26(4), 539-564.

[7] S. Chu, Science, 2009. 325(5948), 1599.

[8] J.C. Abanades, E.S. Rubin, M. Mazzotti, H.J. Herzog, Energy Environ. Sci., 2017, 10(12), 2491-2499.

[9] F.M. Baena-Moreno, M. Rodríguez-Galán, F. Vega, B. Alonso-Fariñas, L.F. Vilches Arenas, B. Navarrete, Energy Sources Part A: Recovery, Utilization, E. Effects, 2019, 41(12), 1403-1433.

[10] N. Mac Dowell, P.S. Fennell, N. Shah, G.C. Maitland, Nat. Clim. Change., 2017, 7(4), 243-249.

[11] A.S.R. Machado, A.V. Nunes, M.N. da Ponte, J. Supercrit. Fluid., 2018, 134, 150-156.

[12] M.E. Dry, Catal. Today, 2002, 71(3-4), 227-241.

[13] S. Hernández, M.A. Farkhondehfal, F. Sastre, M. Makkee, G. Saracco, N. Russo, Green Chem., 2017, 19(10), 2326-2346.

[14] Y. Chen, C.W. Li, M.W. Kanan, J. Am. Chem. Soc., 2012, 134(49), 19969-19972.
[15] W. Zhu, R. Michalsky, O.n. Metin, H. Lv, S. Guo, C.J. Wright, X. Sun, A.A. Peterson, S. Sun, J. Am. Chem. Soc., 2013, 135(45), 16833-16836.

[16] H. Mistry, R. Reske, Z. Zeng, Z.-J. Zhao, J. Greeley, P. Strasser, B.R. Cuenya, J. Am. Chem. Soc., 2014, 136(47), 16473-16476.

[17] W. Zhu, Y.-J. Zhang, H. Zhang, H. Lv, Q. Li, R. Michalsky, A.A. Peterson, S. Sun, J. Am. Chem. Soc., 2014, 136(46), 16132-16135.

[18] S. Back, M.S. Yeom, Y. Jung, ACS Catal., 2015, 5(9), 5089-5096.

[19] J.-H. Kim, H. Woo, S.-W. Yun, H.-W. Jung, S. Back, Y. Jung, Y.-T. Kim, Appl. Catal. B-Environ., 2017, 213, 211-215.

[20] X. Peng, S.G. Karakalos, W.E. Mustain, ACS Appl. Mater. Interfaces., 2018, 10(2), 1734-1742.

[21] J. Rosen, G.S. Hutchings, Q. Lu, R.V. Forest, A. Moore, F. Jiao, ACS Catal., 2015, 5(8), 4586-4591.

[22] W. Luo, J. Zhang, M. Li, A. Zu?ttel, ACS Catal., 2019, 9(5), 3783-3791.

[23] Z. Weng, J. Jiang, Y. Wu, Z. Wu, X. Guo, K.L. Materna, W. Liu, V.S. Batista, G.W. Brudvig, H. Wang, J. Am. Chem. Soc., 2016, 138(26), 8076-8079.

[24] J. Choi, M.J. Kim, S.H. Ahn, I. Choi, J.H. Jang, Y.S. Ham, J.J. Kim, S.-K. Kim, Chem. Eng. J., 2016, 299, $37-44$.

[25] W. Luc, C. Collins, S. Wang, H. Xin, K. He, Y. Kang, F. Jiao, J. Am. Chem. Soc., 2017, 139(5), 1885-1893.

[26] F. Jia, X. Yu, L. Zhang, J. Power Sources, 2014, 252, 85-89.

[27] Y. Mun, S. Lee, A. Cho, S. Kim, J.W. Han, J. Lee, Appl. Catal. B-Environ., 2019, 246, 82-88.

[28] C. Delacourt, P.L. Ridgway, J.B. Kerr, J. Newman, J. Electrochem. Soc., 2008, 155(1), B42-B49.

[29] C. Delacourt, J. Newman, J. Electrochem. Soc., 2010, 157(12), B1911.

[30] E.J. Dufek, T.E. Lister, M.E. McIlwain, J. Appl. Electrochem., 2011, 41(6), 623-631.

[31] E.J. Dufek, T.E. Lister, S.G. Stone, M.E. Mcllwain, J. Electrochem. Soc., 2012, 159(9), F514.

[32] Y.H. Chung, M.G. Ha, Y. Na, H.Y. Park, H.J. Kim, D. Henkensmeier, S.J. Yoo, J.Y. Kim, S.Y. Lee, S.W. Lee, H. S. Park, Y-T Kim, J. H. Jang, Electroanalysis, 2019, 31(7), 1401-1408.

[33] S. Zhang, P. Kang, S. Ubnoske, M.K. Brennaman, N. Song, R.L. House, J.T. Glass, T.J. Meyer, J. Am. Chem. Soc., 2014, 136(22), 7845-7848.

[34] A. Goyal, G. Marcandalli, V.A. Mints, M.T.M. Koper, J. Am. Chem. Soc., 2020, 142(9), 4154-4161.

[35] A.J. Bard, L.R. Faulkner, Electrochemical Methods, 2001, 2(482), 580-632. 